\title{
Sarcoide equino associado ao papilomavírus bovino BR-UEL-4
}

\author{
Equine sarcoid associated with bovine papillomavirus BR-UEL-4
}

\begin{abstract}
Bruno Leite dos Anjos ${ }^{\mathrm{I}, \mathrm{III} *}$ Mariana Sá e Silva ${ }^{\mathrm{II}}$ Aline Diefenbach ${ }^{\mathrm{I}}$ Marilene de Farias Brito $^{\mathrm{III}}$ Gilberto dos Santos Seppa ${ }^{\text {IV }}$ Mário Celso Sperotto Brum ${ }^{\mathrm{V}}$
\end{abstract}

\section{- NOTA -}

\section{RESUMO}

Um equino, sem raça definida, macho com três anos de idade apresentou múltiplos nódulos na pele, em diversas regiões do corpo. As lesões localizavam-se predominantemente nos lábios, nas bochechas, na região submandibular e na região inguinal direita. Os tumores caracterizavam-se como sarcoides dos tipos misto, fibroblástico, verrucoso e oculto. Histologicamente apresentaram proliferação de fibroblastos dérmicos, muitas vezes ulcerado, com ou sem hiperplasia pseudoepiteliomatosa da epiderme e formação de pequenos grupos isolados de fibroblastos neoplásicos na derme superficial. Três amostras de tecido foram submetidas à extração de DNA e amplificação por PCR com oligonucleotídeos iniciadores genéricos direcionados para uma região interna do gene L1 dos papilomavírus. Os produtos resultantes da amplificação de duas amostras foram sequenciados $e$ demonstraram identidade de $99 \%$ com o papilomavírus bovino (BPV) BR-UEL-4. Essa é a primeira descrição da infecção de equinos, bem como de sua associação com sarcoide pelo BPV $B R-U E L-4$, um suposto novo tipo de BPV identificado recentemente no Brasil a partir de papilomas cutâneos em bovinos.

Palavras-chave: doenças de equinos, patologia, papilomavírus bovino, BR-UEL-4, sarcoide, PCR.

\section{ABSTRACT}

A 3-year-old, mixed breed, male horse showed multiple nodules in different areas of the skin. Lesions occurred predominantly on the lips, cheeks, and submandibular and right inguinal regions. The nodules were characterized as mixed, fibroblastic, verrucous and occult types of sarcoid. Histologically there was proliferation of dermal fibroblasts, with or without pseudoepitheliomatous hyperplasia of the epidermis (frequently ulcerated), and formation of small isolated groups of neoplastic fibroblasts in the superficial dermis. Three tissue samples were submitted to DNA extraction and PCR amplification with generic primers for the internal region of the papillomavirus $L 1$ gene. The amplified products from two samples were sequenced and showed 99\% identity with the bovine papillomavirus (BPV) BR-UEL-4. This is the first description of BPV BR-UEL-4 infecting a horse and causing sarcoid in this species. BPV BR-UEL-4 is a putative new $B P V$ type recently identified in skin papillomas in a Brazilian cattle herd.

Key words: horse diseases, pathology, bovine papillomavirus, BR-UEL-4, sarcoid, PCR.

Sarcoide equino ou fibropapiloma é um neoplasma benigno, não-metastático, formado por componentes epidermais e dermais frequentemente observados na pele de equinos, asininos e muares. Esse tumor afeta principalmente cavalos com idade entre três e seis anos, apresenta-se localmente invasivo, embora seu comportamento seja benigno. Sua forma

ICurso de Pós-graduação em Ciências Veterinárias, área de concentração em Patologia Veterinária, Universidade Federal Rural do Rio de Janeiro (UFRRJ), 23890-000, Seropédica, RJ, Brasil. E-mail: anjosje@yahoo.com.br. *Autor para correspondência.

IIDepartamento de Medicina Veterinária Preventiva (DMVP), Universidade Federal de Santa Maria (UFSM), 97105-900, Santa Maria, RS, Brasil.

IIILaboratório de Patologia Veterinária (LAPAV), Departamento de Epidemiologia e Saúde Pública, UFRRJ, Seropédica, RJ, Brasil.

${ }^{\text {IV } H o s p i t a l ~ V e t e r i n a ́ r i o ~ d e ~ G r a n d e s ~ A n i m a i s, ~ I n s t i t u t o ~ d e ~ V e t e r i n a ́ r i a, ~ U F R R J, ~ S e r o p e ́ d i c a, ~ R J, ~ B r a s i l . ~}$

vUniversidade Federal do Pampa (UNIPAMPA), Uruguaiana, RS, Brasil. 
maligna é rara (GOLDSCHMIDT \& HENDRICK, 2002; KNOTTENBELT et al., 2005). Esses tumores podem ocorrer de forma solitária ou disseminada pelo corpo. Áreas como cabeça, lábios, membros e abdome ventral são mais comumente afetadas, bem como locais próximos a traumas (GOLDSCHMIDT \& HENDRICK, 2002).

Atualmente a infecção por papilomavírus bovino (BPV) é entendida como a causa do desenvolvimento de sarcoides em equídeos (NASIR \& CAMPO, 2008). A família Papillomaviridae é composta por 18 gêneros, dos quais quatro são compostos por diferentes espécies de BPV, destacando-se os Deltapapillomavirus (BPV-1 e 2), Xipapillomavirus (BPV-3, 4, 6, 9 e 10), Epsilonpapillomavirus (BPV-5 e 8), e um gênero ainda não classificado (BPV-7) (HATAMA et al., 2008). A identificação e classificação das espécies virais baseiam-se na homologia de regiões genômicas, especialmente do gene L1, que codifica a proteína mais importante do capsídeo viral (BORZACCHIELLO \& ROPERTO, 2008). Recentemente, os BPV BR-UEL-2 a 5 foram identificados no Brasil, associados com papilomas na pele de bovinos (CLAUS et al., 2008). No entanto, não há relato da ocorrência desses papilomavírus em associação a lesões cutâneas em outras espécies animais (CLAUS et al., 2008; HATAMA et al., 2008). O objetivo deste trabalho foi relatar um caso de sarcoide associado ao BPV BR-UEL-4 em um equino, no Estado do Rio de Janeiro.

Em março de 2008, um equino com três anos de idade foi encaminhado ao Hospital de Grandes Animais (HVGA) da Universidade Federal Rural do Rio de Janeiro por apresentar massas tumorais cutâneas em diversas regiões do corpo. As lesões iniciaram há aproximadamente 2,5 anos, após traumatismo cortante na pele, próximo à articulação metacarpo-falangeana esquerda. $\mathrm{O}$ animal era mantido em contato com bovinos que também apresentavam lesões verrucosas na pele. Clinicamente, o animal encontrava-se em bom estado corporal, com eritrograma, leucograma, plaquetograma, bioquímica sérica e urinálise normais. A remoção cirúrgica e os tratamentos homeopáticos, como acupuntura e auto-hemoterapia, não apresentaram resultados satisfatórios. Os nódulos ulcerados eram tratados com unguento e sulfadiazina tópica contra infecções secundárias. Foram observados episódios de febre.

Macroscopicamente, as lesões foram classificadas, em ordem de maior ocorrência, como sarcoides dos tipos misto, fibroblástico, verrucoso e oculto. Os nódulos variaram entre 1 e $18 \mathrm{~cm}$ de diâmetro, com superfície multilobulada com ou sem crostas e superfície de corte brancacenta. Os tumores foram observados com maior frequência na pele das regiões submandibular (Figura 1A) e palpebral esquerda, na lateral do pescoço, na região inguinal próximo aos testículos e na base da cauda (Figura 1B), na região peitoral e nas áreas distais dos membros torácicos e pélvicos. A maioria dos nódulos apresentava superfície irregular e, por vezes, com acentuada queratinização com aspecto filiforme e eram bastante firmes. Os nódulos maiores apresentavam consistência fibroelástica, superfície alopécica, levemente rugosa e muitos deles eram ulcerados. Pequenos nódulos também foram observados no tecido subcutâneo da região massetérica e peitoral. Fragmentos dos nódulos foram coletados por meio de biópsia incisional, sob sedação com acepromazina $1 \%$ e anestesia local com lidocaína $2 \%$. Cerca de três meses após a coleta dos fragmentos, o animal apresentou quadro clínico de cólica impactante e foi submetido à eutanásia de acordo com as normas éticas de bem-estar animal. Os achados de necropsia confirmaram o diagnóstico clínico de cólica por impactação do cólon maior.

Os fragmentos foram processados rotineiramente para histopatologia e corados pela hematoxilina e eosina. Ao exame microscópico, os nódulos eram formados por intensa proliferação de fibroblastos dérmicos e ou acentuada hiperqueratose paraqueratótica, com áreas de ulceração da epiderme e projeções pseudoepiteliomatosas (rete ridges) que, por vezes, formavam pequenas ilhas de fibroblastos encarcerados (Figura 1C). O componente dérmico visto nos tipos fibroblástico, misto e oculto, apresentava intensa proliferação de fibroblastos e fibras colágenas arranjados em feixes entrelaçados, emaranhados ou em redemoinhos. Os fibroblastos apresentavam núcleo redondo ou alongado com cromatina frouxa e nucléolo por vezes proeminente e leve pleomorfismo. Os sarcoides mistos apresentavam fibroblastos perpendiculares na junção dermo-epidérmica (picketfence) (Figura 1D).

Três fragmentos de tumores foram coletados sob refrigeração e submetidos à extração de DNA e detecção do genoma viral. A extração de DNA viral foi realizada a partir de uma suspensão de $100 \mathrm{mg}$ dos tumores em $900 \mu \mathrm{L}$ de tampão de lise [10mM Tris, $10 \mathrm{mM}$ EDTA (TE), 0,5\% Nonited, $1 \%$ SDS, $0,001 \mathrm{mg} \mathrm{mL}^{-1}$ proteinase $\mathrm{K}$ ] e incubados por $1 \mathrm{~h}$ a $56^{\circ} \mathrm{C}$. O DNA foi extraído com fenol:clorofórmio (1:1), precipitado com etanol absoluto por $2 \mathrm{~h}$ a $20^{\circ} \mathrm{C}$, centrifugado e ressuspenso em tampão TE. Na PCR, para a amplificação parcial do gene $\mathrm{L} 1$, foram utilizados $2 \mu \mathrm{L}$ do DNA extraído (aproximadamente $1 \mu \mathrm{g}$ de DNA total) e $48 \mu \mathrm{L}$ de mix $(0,5 \mu \mathrm{M}$ de cada primer; $200 \mu \mathrm{M}$ dNTPs, 


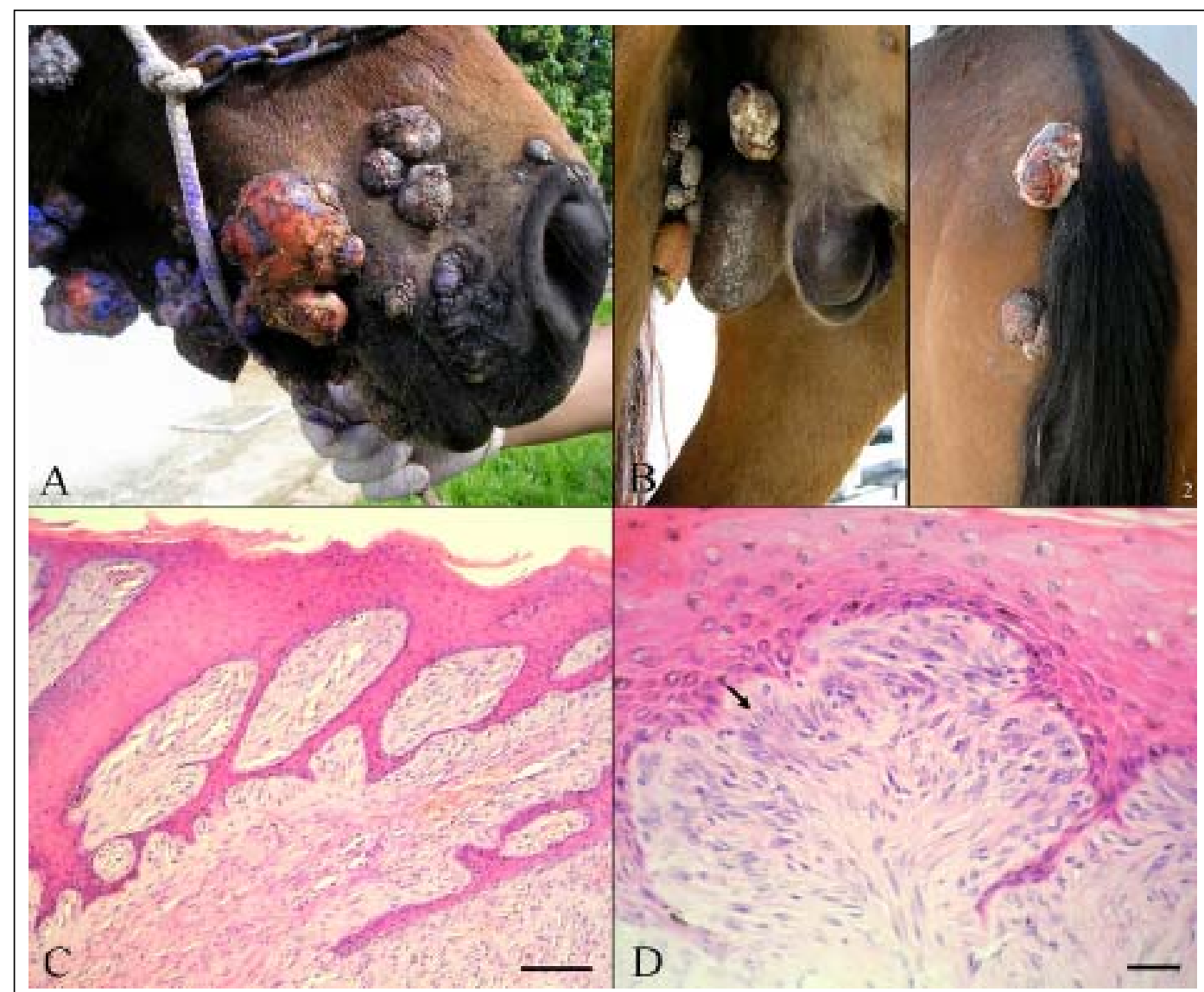

Figura 1 - Sarcoide associado ao papilomavírus bovino BR-UEL-4 em um equino. A. Equino apresentando múltiplos nódulos tumorais com até $10 \mathrm{~cm}$ de diâmetro na cabeça, com superfície crostosa e irregular. Alguns nódulos estão ulcerados. B. Aspecto macroscópico de nódulos tumorais na região inguinal, próximos ao prepúcio (1) e na base da cauda (2). C. Aspecto histológico do sarcoide misto caracterizado por proliferação de fibroblastos dérmicos, moderada acantose com projeções pseudoepiteliomatosas em direção à derme (rete ridges) e formação de ilhas de fibroblastos encarcerados. Barra $=250 \mu \mathrm{m}$. D. Sarcoide do tipo misto com proliferação de fibroblastos orientados perpendicularmente à epiderme (picket-fence) (seta). Barra $=75 \mu \mathrm{m}$.

tampão de reação $1 \mathrm{X}, 2,5 \mu \mathrm{M} \mathrm{MgCl}_{2}$ e $1 \mathrm{UI}$ Taq polimerase (Invitrogen). Os primers utilizados foram: FAP 59 (5'-TAACWGTIGGICAYCCWTATT-3') e FAP 64 (5'-CCWATATCWVHCATITCICCATC-3) (FORSLUND et al., 1999). As condições utilizadas para amplificação foram: $94^{\circ} \mathrm{C}$ por $5 \mathrm{~min}$, seguido de 40 ciclos: desnaturação $\left(94^{\circ} \mathrm{C}, 50 \mathrm{~s}\right)$, anelamento $\left(58^{\circ} \mathrm{C}, 55 \mathrm{~s}\right)$ e extensão $\left(72^{\circ} \mathrm{C}, 1 \mathrm{~min}\right)$. Os produtos de PCR de duas amostras foram analisados em gel de agarose $(1,5 \%)$, observados sob luz ultravioleta e posteriormente purificados (PureLink-Invitrogen) e sequenciados em triplicata (MegaBace 1000). As sequências foram analisadas e montadas com o auxílio do pacote Staden (STADEN, 1996). As amostras do sarcoide dos tipos misto e oculto foram positivas para o BPV com a amplificação de um produto com aproximadamente $478 \mathrm{pb}$. A análise das sequências gerou um consenso de 453pb (amostra 1) e 471pb (amostra 2), e ambos os consensos apresentaram homologia de nucleotídeos de $99 \%$ com o isolado BR-UEL-4 (n. acesso no GenBank EU293540.1). A diferença de 1\% entre o primeiro relato de BR-UEL-4 e a sequência identificada neste caso pode indicar uma variante viral adaptada ao outro hospedeiro.

Os tumores descritos nesse caso apresentaram características macroscópicas e microscópicas idênticas às observadas em sarcoides equídeos; são formados por população densa de células mesenquimais semelhantes a fibroblastos, redondas ou fusiformes, com ou sem hiperplasia da epiderme (GOLDSCHMIDT \& HENDRICK, 2002). Os sarcoides dos tipos misto e fibroblástico foram os mais observados nesse estudo, seguidos pelos tipos verrucoso e oculto. Diferenças histológicas são observadas entre os diferentes sarcoides; no tipo 
verrucoso são comuns a hiperplasia da epiderme com queratinização acentuada e infrequente proliferação de fibroblastos dérmicos; o tipo fibroblástico apresentase mais firme, circunscrito e formado por intensa proliferação de fibroblastos e colágeno, com frequência são ulcerados e apresentam variada reação hiperplásica da epiderme; o tipo oculto consiste em massas nodulares de variados tamanhos, no tecido subcutâneo, formadas por intensa proliferação de fibroblastos e colágeno; o tipo misto, em geral, apresenta combinação entre as formas verrucosa, fibroblástica e oculta (GOLDSCHMIDT \& HENDRICK, 2002; HARGIS \& GINN, 2007).

Muitas das massas tumorais observadas nesse equino estavam localizadas em áreas de difícil acesso cirúrgico e boas margens de segurança nem sempre foram possíveis, possibilitando recidivas e o surgimento de novos nódulos. Esse comportamento tumoral já foi observado em diversos casos de sarcoide equino (KNOTTENBELT et al., 2005; NASIR \& CAMPO, 2008).

A detecção e identificação do genoma viral demonstram a associação do BPV BR-UEL-4 com sarcoide equino, contribuindo no diagnóstico histopatológico. O contato desse animal com bovinos que apresentavam lesões papilomatosas reforçaram o envolvimento viral na patogênese das lesões. A variante viral BR-UEL-4 foi inicialmente identificada no Brasil em bovinos com lesões papilomatosas na região auricular e do pescoço de bovinos. Esse vírus foi classificado como uma nova espécie por apresentar homologia inferior a $88 \%$ com amostras já conhecidas (CLAUS et al., 2008). O BPV BR-UEL-4 possui grande similaridade com o BPV-2, agente reconhecidamente presente em casos de sarcoide equino (CLAUS et al., 2008; NASIR \& CAMPO, 2008). No entanto, a não identificação de antígenos de BPV intratumorais e de anticorpos neutralizantes anti-BPV no soro de cavalos afetados sugerem uma infecção viral não-produtiva (GOLDSCHMIDT \& HENDRICK, 2002; NASIR \& CAMPO, 2008). Estudos recentes já demonstraram transcrições oncogênicas específicas de diversos BPV que apontam para o envolvimento viral direto na patogênese desses tumores em equídeos (NASIR \& CAMPO, 2008). Essa é a primeira descrição da infecção pelo BPV BR-UEL-4 associado a sarcoide em equinos no Brasil.

\section{REFERÊNCIAS}

BORZACCHIELLO, G.; ROPERTO, F. Bovine papillomaviruses, papillomas and cancer in cattle. Veterinary Research, v.39, n.5, p.45, 2008. Disponível em: <http://dx.doi.org/10.1051/ vetres:2008022>. Acesso em: 26 abr. 2010. doi: 10.1051/ vetres: 2008022 .

CLAUS, M.P. et al. Identification of unreported putative new bovine papillomavirus types in Brazilian cattle herds. Veterinary Microbiology, v.132, n.3-4, p.396-401, 2008. Disponível em: $<$ http://dx.doi.org/10.1016/j.vetmic.2008.05.026>. Acesso em: 28 ago. 2009. doi: 10.1016/j.vetmic.2008.05.026.

FORSLUND, O. et al. A broad range of human papillomavirus types detected with a general PCR method suitable for analysis of cutaneous tumours and normal skin. Journal of General Virology, v.80, n.9, p.2437-2443, 1999. Disponível em: $<$ http://vir.sgmjournals.org/cgi/content/full//80/9/2437>. Acesso em: 26 abr. 2010. doi: 10501499.

GOLDSCHMIDT, M.H.; HENDRICK, M.J. Tumors of the skin and soft tissues. In: MEUTEN, D.J. Tumors in domestic animals. Ames: Iowa State, 2002. Cap.2, p.46-117.

HATAMA, S. et al. Genomic and phylogenetic analysis of two novel bovine papillomaviruses, BPV-9 and BPV-10. Journal of General Virology, v.89, n.1, p.158-163, 2008. Disponível em: <http://vir.sgmjournals.org/cgi/content/full/89/1/158>. Acesso em: 26 abr. 2010. doi: 18089739.

HARGIS, A.M.; GINN, P.E. The integument. In: McGAVIN, M.D.; ZACHARY, J.F. Pathologic basis of veterinary disease. St Louis: Mosby, 2007. Cap.17, p.1107-1261.

KNOTTENBELT, D.C. A suggested clinical classification for the equine sarcoid. Clinical Techniques in Equine Practice, v.4 p.278-295, 2005. Disponível em: <http://www.clinicalequine.com/ article/S1534-7516(05)00106-X>. Acesso em: 20 set. 2009. doi: 10.1053/j.ctep.2005.10.008

NASIR, L.; CAMPO, M.S. Bovine papillomaviruses: their role in the aetiology of cutaneous tumours of bovids and equids. Journal Compilation, v.9, p.243-254, 2008. Disponível em: <http://www3.interscience.wiley.com/journal/121372333/ abstract?CRETRY $=1 \&$ SRETRY $=0>$. Acesso em: 16 maio, 2009. doi: $10.1111 / \mathrm{j} .1365-3164.2008 .00683 . \mathrm{x}$.

STADEN, R. The Staden sequence analysis package. Molecular Biotechnology, v.5, n.3, p.233-241, 1996. Disponível em: $<$ http http://www.springerlink.com/content/r31r73r76k05/ $? \mathrm{p}=9 \mathrm{aeab} 45 \mathrm{adb} 1 \mathrm{f} 49 \mathrm{bdab} 1775 \mathrm{~b} 859 \mathrm{f} 4638 \mathrm{~d} \& \mathrm{pi}=118>$. Acesso em: 26 abr. 2010. doi: 10.1007/BF02900361. 